\title{
Work In Progress: A Snapshot of OER Adoption in Engineering Mechanics Courses
}

\section{Dr. Jacob Preston Moore, Pennsylvania State University, Mont Alto}

Jacob Moore is an Assistant Professor of Engineering at Penn State Mont Alto. He has a PhD in Engineering Education from Virginia Tech and a Bachelors and Masters in Mechanical Engineering. His research interests include concept mapping, digital textbooks, and additive manufacturing.

\section{Dr. Thomas L. Reinsfelder, Pennsylvania State University, Mont Alto}

Thomas L. Reinsfelder MSLS, PhD is Interim Head Librarian at Penn State Mont Alto and serves as co-editor of the online journal Pennsylvania Libraries: Research \& Practice. His interests include open educational resources (OER) and open access scholarly publishing. 


\section{Work In Progress: A Snapshot of OER Adoption in Engineering Mechanics Courses}

\section{Introduction and Motivation:}

The purpose of this work is to determine the extent to which Open Educational Resources (OER) are used in introductory engineering mechanics courses, and to examine the barriers to adoption in these courses. According to the William and Flora Hewlett Foundation "Open Educational Resources are teaching, learning, and research resources that reside in the public domain or have been released under an intellectual property license that permits their free use and repurposing by others. OER include full courses, course materials, modules, textbooks, streaming videos, tests, software, and any other tools, materials, or techniques used to support access to knowledge." [1].

When compared to traditionally published content, OER can have several advantages. First and foremost to many students, OER are free to access digitally or available at a low cost if offered as a physical copy. The College Board advises that students budget between $\$ 1220$ and $\$ 1420$ a year for books and supplies during the 2017-2018 academic year [2], and the cost of college textbooks has been rising at a rate that far exceeds the rate of inflation for decades [3]. Additionally, researchers have found that as much as $65 \%$ of students have skipped buying or renting a textbook for a course because of the cost even when nearly all (94\%) of those students thought it hurt their grades in the course [4]. OER has the potential to not only save students money, but also help ensure equal access to course materials leading to higher rates of student success across the board.

In addition to eliminating textbook or other course materials costs for students, OER can also be repurposed, remixed, and updated continuously. This gives instructors full control over the learning resources they make available to the class, giving each instructor the opportunity to tune the resources they use to their specific audience and address any needed changes in the moment.

As discussed more fully in the literature review that follows, there is research examining the use of OER broadly in higher education, but there is currently very little research examining the use of OER specifically in engineering programs. This research examines the use of OER in three engineering mechanics courses (statics, dynamics, and strength of materials) as a bellwether for more widespread adoption of OER in engineering programs. These courses were identified as a logical first step in the widespread adoption of OER for three specific reasons. First, these courses are taken by students across a variety of majors by a large number of students. Second, unlike math or science courses, these courses are usually taught by engineering faculty and are under the control of engineering departments. Third, unlike introductory design courses or introductory programming courses, these courses have fairly consistent content from one institution to the next. For these reasons, the authors felt that the engineering mechanics courses represent the best way for a few high-quality OER resources to have the largest impact on students, the largest return on investment if you will. 


\section{Literature Review:}

\subsection{The History and Use of OER in Higher Education}

Pinning down the exact origins of offering freely available and modifiable learning content is hard because of the simplicity of the idea, but without a doubt, having digital content has made free distribution much more viable in the past few decades. In 2001, MIT started the Open Courseware Initiative, arguably the first widely used OER platform with more than a million users before 2007 [5]. This system continues to provide access to MIT course materials and contains everything from lecture notes to full-scale courses. Other significant contributors to OER at present, including the Khan Academy [6] and OpenStax (formerly Connexions) [7] have also reported many millions of user accesses.

Despite the high numbers of users for some of these OER platforms, a 2017 report by Seaman and Seaman [8] found that open textbooks represented only $9 \%$ of the textbook market for the 2016-17 academic year. This represents a large increase over the 5\% reported for the previous year (2015-2016), but it still leaves a lot of room for expansion. Large, introductory, multisection courses in particular seem to be leading the pack in terms of open textbook adoption, with an adoption rate of $16.5 \%$. The market share for OpenStax books, the largest OER player in higher education, currently rivals that of many of their commercial competitors demonstrating that OER publishers can compete with traditional publishing.

Despite significant gains in the market, barriers still exist to the adoption of OER. Seaman and Seaman [8] found that only $30 \%$ of the surveyed faculty members were "aware" or "very aware" of OER. Additionally, nearly half of faculty reported that there were not sufficient OER options in their subject area and half reported they lacked the time needed to review and vet new possible resources. Making OER easier to find and providing reviews by other trusted faculty could help to address these two common barriers to adoption.

\subsection{The Learning Effectiveness of OER}

In addition to examining adoption, it is also important to consider student learning as a factor. OER is a broad category that potentially encompasses a wide range of resources, and understandably, the learning effectiveness of resources can vary from one to the next. Most faculty indicate that they will only adopt OER in place of commercial textbooks if they feel the OER is of greater or equal quality [9]. When looking broadly on the impact of OER on student performance across a variety of courses, Winitzky-Stephens and Pickavance [10] and Allen et. al [11] found no significant difference between courses using OER and courses using commercial textbooks. In other studies focusing on isolated classes however, gains in student learning have been observed with the adoption of OER in the classroom [12]-[14]. Fundamentally, the concept of "open" resources is about access to the content. It is quality of the content that is being made "open" that ultimately determines the effect on student learning. 


\section{Research Questions and Methods:}

\subsection{Research Questions and Study Design:}

This research seeks to address two primary research questions. First, since no previous work seems to examine the current adoption of OER in engineering mechanics courses specifically, we must ask the question below to establish a baseline.

\section{RQ1: What is the current balance between open content and traditionally published content in engineering mechanics courses?}

Second, in order to understand how the adoption of OER might be expanded in engineering mechanics courses in the future, we ask the second research question.

\section{RQ2: What barriers exist to the adoption of open resources in engineering courses, and how might those barriers be overcome?}

To address the above research questions, the authors developed a plan to gather data from two sources: the first is publicly available information regarding the required course materials from randomly selected institution websites; the second is a survey instrument distributed to instructors of engineering mechanics courses. As a work in progress paper, the authors here will present an overview of the data gathered from publicly available websites on resources used in engineering mechanics courses.

\subsection{Study Population:}

To obtain an objective cross section of engineering programs, the authors started by randomly selecting institutions from the list of ABET accredited programs [15]. Twenty institutions were selected in each of four categories for eighty total institutions examined. The four categories are detailed in Table 1. The categories were used to ensure that large institutions with many accredited programs did not dominate the results.

Institutions with distinct campuses or separate institutions in the same system were categorized individually. For example, a branch campus of a larger university would be counted as an undergraduate only college if there were no graduate engineering degrees offered on that campus, even if graduate degrees were offered at the main campus of the university.

Data on these institutions was collected from the institutional websites; including mechanics class sections, required course materials, and instructor contact information. 
Table 1: Institutional Categories

\begin{tabular}{|c|c|c|}
\hline Category & Definition & Number of Universities \\
\hline $\begin{array}{c}\text { Two Year } \\
\text { Colleges }\end{array}$ & $\begin{array}{c}\text { Universities that offer no accredited four year } \\
\text { engineering or engineering technology degrees }\end{array}$ & 20 \\
\hline $\begin{array}{c}\text { Undergraduate } \\
\text { Only Colleges }\end{array}$ & $\begin{array}{c}\text { Universities that offer no graduate programs in } \\
\text { engineering or engineering technology } \\
\text { (accredited or otherwise) but do offer accredited } \\
\text { four year undergraduate degrees }\end{array}$ & 20 \\
\hline $\begin{array}{c}\text { Public } \\
\text { Research } \\
\text { Universities }\end{array}$ & $\begin{array}{c}\text { Public universities that offer at least one graduate } \\
\text { program in engineering or engineering } \\
\text { technology. }\end{array}$ & 20 \\
\hline $\begin{array}{c}\text { Private } \\
\text { Research } \\
\text { Universities }\end{array}$ & $\begin{array}{c}\text { Private universities that offer at least one } \\
\text { graduate program in engineering or engineering } \\
\text { technology. }\end{array}$ & 20 \\
\hline
\end{tabular}

For the survey data, the survey instrument was distributed directly to the instructors identified at the 80 selected institutions as well as being sent to the ASEE mechanics division membership list. The survey can offer insights into the motivations of instructors, though there is the possibility of a self-selection bias. Using the publicly available data from randomly selected universities is intended to combat some of that self-selection bias.

\subsection{Data Collection Procedures:}

After identifying institutions to be used in the analysis, the authors had to first identify the relevant courses at those institutions. These were courses that fit broadly into the statics, dynamics, and strengths of materials categories and courses that represent any combination of these subjects. The recommended academic plans for mechanical engineering programs as well as the course descriptions were used at a starting point in most cases, though each institution website was a little different. As an instructor who regularly teaches each of these subjects, the first author served as the authority as to which courses counted as "introductory mechanics" courses.

After the relevant course designations were determined, for most institutions the authors could use publicly available class search functions on the institutional website to identify any sections of the courses offered during the 2017-2018 academic year as well as course instructors and required course materials. Finally, the contact information for the listed course instructors could often be found via faculty directories. This contact information will be used in phase two of the research, focusing on surveys sent to mechanics instructors.

\section{Results and Discussion:}

As a work in progress paper, this paper will only discuss the results of the data collection from the publicly available websites, as the survey responses are still being collected and analyzed. 
We must note that the data collected is only a sample of observable data at a given time and because not all institutions make information available in a consistent or public way, the numbers reported here might not be complete or representative of all engineering mechanics courses.

That being said, of 80 institutions investigated, significant observations include:

- Almost no OER was listed in the course materials from the observed institutions. The one clear example of a course using OER was the "Freeform Lecturebook" [16] being used at Purdue University in statics, dynamics and strength of materials. If OER is being used elsewhere, it is not being formally listed in the course materials.

- Outside of OER, we did find two other measures to control costs. One college (Indiana Institute of Technology) has implemented a policy where all textbooks are included in the cost of tuition. A course section at a second institution listed the textbook as optional, with the instructor presumably accounting for students who did not buy the textbook.

- Nearly all of the other course sections appear to be using traditional commercially available textbooks for the mechanics courses. Additionally, two sets of books (The Hibbler mechanics texts, and the Beer and Johnston mechanics texts) appear to dominate the market for commercially available texts.

- There were 26 instances where access codes for supplemental materials were required or recommended in addition to the commercial textbook. This is less than a majority of the examined courses, but it is also not an uncommon practice to require these supplemental commercial materials.

The authors were able to identify courses but were unable to identify any course materials for 34 of the 240 institution and course combinations ( 80 universities $x$ three mechanics courses). Some of these sections may be using OER, some may not require any course textbooks, but publicly accessible information did not permit positive confirmation of course materials in every section of every course. In the majority of these cases, the course materials seemed to be behind a login screen of some sort. This represents weakness in the use of publicly available data, but this data will later be combined with survey data to try to get a fuller picture.

In addition to the types of books, the authors also gathered data on the pricing of the textbooks when available. Table 2 below represents a summary of the pricing information that was available via the institutional website. These values represent the prices per course for textbooks.

Table 2: Summary of Textbook Prices across All Institutions and Courses

\begin{tabular}{|c|c|c|c|c|}
\hline $\mathrm{N}=167$ & Minimum & Median & Maximum & Mean \\
\hline & $\$ 69.47$ & $\$ 218.75$ & $\$ 304.00$ & $\$ 212.03$ \\
\hline
\end{tabular}


The information in Table 3 represents the prices of new, print textbooks. In many cases, used textbooks, electronic versions, or textbooks were available. Each of these options would reduce student costs, but the information on options varied greatly from one institution to the next.

Breaking down the median prices by institution type and by course, the researchers also looked for any patterns in terms of certain types of universities being more cost conscious or certain courses having cheaper options be more prevalent. Medians represent the middle value with 50\% of costs over the listed price and $50 \%$ below the listed price. This was chosen over the mean because of the clearly non-normal price distributions.

The results of the breakdown can be seen in Table 3. Shading was used to highlight the highest and lowest costs to help identify patterns. We found no observable patterns in the costs of mechanics textbooks.

Table 3: A Breakdown of Median Textbook Prices by Institution Type and Course.

\begin{tabular}{|l|c|c|c|c|}
\hline $\begin{array}{c}\text { Type of } \\
\text { Institution }\end{array}$ & 2-Year & Undergrad Only & Research Public & $\begin{array}{c}\text { Research } \\
\text { Private }\end{array}$ \\
\hline Statics & $\$ 214.50$ & $\$ 234.50$ & $\$ 211.00$ & $\$ 224.00$ \\
\hline Dynamics & $\$ 245.20$ & $\$ 218.75$ & $\$ 202.42$ & $\$ 194.10$ \\
\hline Strengths & $\$ 210.40$ & $\$ 275.20$ & $\$ 213.35$ & $\$ 244.25$ \\
\hline
\end{tabular}

\section{Conclusions and Future Work:}

As a work in progress, there is clear work to be done to add to this research. The data gathered from public websites at randomly selected institutions provides a snapshot of the current usage trends for OER in engineering mechanics courses. As seen in the data, the use of OER in these courses is very rare. With the textbook market in these courses dominated by two sets of textbooks however, it is easy to see how even a single tool could potentially have widespread impact.

Research question 2 regarding barriers to the adoption of open resources in engineering courses will be addressed through analysis of survey results as viewed through the Rogers Diffusion of Innovation Model. This will also provide specific insight into how OER use might be expanded to the wider engineering audience. 


\section{References:}

[1] William and Flora Hewlett Foundation, "Open Educational Resources," Hewlett Foundation. [Online]. Available: http://www.hewlett.org/strategy/open-educational-resources/. [Accessed: 07Jul-2017].

[2] The College Board, "Average Estimated Undergraduate Budgets, 2017-18 - Trends in Higher Education," Average Estimated Undergraduate Budgets, 2017-18. [Online]. Available:

https://trends.collegeboard.org/college-pricing/figures-tables/average-estimated-undergraduatebudgets-2017-18. [Accessed: 04-Jan-2018].

[3] B. Popken, College Textbook Prices Have Risen 1,041 Percent Since 1977. 2015.

[4] E. Senack, Open Textbooks: The Billion-Dollar Solution. The Student PIRGs. 2014.

[5] H. Abelson, "The Creation of OpenCourseWare at MIT," J Sci Educ Technol, vol. 17, no. 2, pp. 164174, Apr. 2008.

[6] "Khan Academy," Khan Academy. [Online]. Available: http://www.khanacademy.org/about. [Accessed: 23-Jan-2018].

[7] "OpenStax," OpenStax. [Online]. Available: https://openstax.org. [Accessed: 23-Jan-2018].

[8] J. Seaman and J. Seaman, Opening the Textbook: Educational Resources in U.S. Higher Education, 2017. Babson Survey Research Group, 2017.

[9] E. Jung, C. Bauer, and A. Heaps, "Higher Education Faculty Perceptions of Open Textbook Adoption," The International Review of Research in Open and Distributed Learning, vol. 18, no. 4, Jun. 2017.

[10] J. R. Winitzky-Stephens and J. Pickavance, "Open Educational Resources and Student Course Outcomes: A Multilevel Analysis," The International Review of Research in Open and Distributed Learning, vol. 18, no. 4, Jun. 2017.

[11] G. Allen, A. Guzman-Alvarez, M. Molinaro, and D. Larsen, "Assessing the Impact and Efficacy of the Open-Access ChemWiki Textbook Project," Educause Learning Initiative Brief, pp. 1-8, 2015.

[12]Z. QingHua, Z. WeiHua, H. ZheZhi, and D. RongHua, "Improving Aerospace Engineering Students' Achievements by an Open Aero Control Experiment Apparatus," IEEE Transactions on Education, vol. 57, no. 4, pp. 229-234, Nov. 2014.

[13] N. Ackovska and S. Ristov, "OER Approach for Specific Student Groups in Hardware-Based Courses," IEEE Transactions on Education, vol. 57, no. 4, pp. 242-247, Nov. 2014.

[14] M. Llamas-Nistal and F. A. Mikic-Fonte, "Generating OER by Recording Lectures: A Case Study," IEEE Transactions on Education, vol. 57, no. 4, pp. 220-228, Nov. 2014.

[15] ABET, "Find an ABET-Accredited Program." [Online]. Available: http://main.abet.org/aps/accreditedprogramsearch.aspx. [Accessed: 05-Jan-2018].

[16] J. Rhoads, E. Nauman, B. Holloway, and C. Krousgrill, "The Purdue Mechanics Freeform Classroom: A New Approach to Engineering Mechanics Education," presented at the 121st ASEE Annual Conference \& Exposition, Indianapolis, IN, 2014. 